\title{
Pembuatan $\mathrm{Ba}_{0,8} \mathrm{Sr}_{0,2} \mathrm{TiO}_{3}$ menggunakan Metode Co-precipitation dengan Variasi Suhu Sintering
}

\author{
Isma Alvia Nita, Yofentina Iriani*, dan Fahru Nurosyid \\ Program Studi Fisika, Fakultas MIPA, Universitas Sebelas Maret, Surakarta \\ Jl. Ir. Sutami 36A Kentingan, Surakarta57126 \\ *Email: yopen_2005@yahoo.com
}

\section{ABSTRACT}

\begin{abstract}
$\mathrm{Ba}_{0,8} \mathrm{Sr}_{0,2} \mathrm{TiO}_{3}$ was made by co-precipitation method with the sintering temperature of $600^{\circ} \mathrm{C}$, $700^{\circ} \mathrm{C}, 800^{\circ} \mathrm{C}$ and $900^{\circ} \mathrm{C}$ for 4 hours. The sintering temperature was varied to investigate its effect on microstructure and dielectric constant of $\mathrm{Ba}_{0,8} \mathrm{Sr}_{0,2} \mathrm{TiO}_{3}$. The microstructure characterization was performed by X-Ray Diffraction (XRD) instrument. The dielectric constant characterization was perform by LCR meter. The crystal size increased significantly with increasing sintering temperature. Measurements of dielectric constant were performed at range of frequency 0.01 to $100 \mathrm{kHz}$. Dielectric constant value is highest at the lowest frequency. Dielectric constant values ize increased significantly with increasing sintering temperature.
\end{abstract}

Keywords: $\mathrm{BaSrTiO}_{3}$, dielectric constant, co-precipitation method

\section{ABSTRAK}

$\mathrm{Ba}_{0}, \mathrm{Sr}_{0,2} \mathrm{TiO}_{3}$ telah disintes is menggunakan metode co-precipitation dengan suhu sintering $600^{\circ} \mathrm{C}, 700^{\circ} \mathrm{C}, 800^{\circ} \mathrm{C}$ dan $900^{\circ} \mathrm{C}$ selama 4 jam. Suhu sintering divariasi untuk mengetahui pengaruhnya terhadap struktur mikro, morfologi dan sifat listrik $\mathrm{Ba}_{0,8} \mathrm{Sr}_{0,2} \mathrm{TiO}_{3}$. Karakterisasi struktur mikro dilakukan menggunakan instrumen X-Ray Diffraction (XRD). Karakterisasi konstanta dielektrik menggunakan instrumen Inductance-Capacitance-Resistance meters (LCR) meter. Variasi suhu sintering berpengaruh terhadap ukuran kristal $\mathrm{Ba}_{0,8} \mathrm{Sr}_{0,2} \mathrm{TiO}_{3}$. Ukuran kristal semakin besar seiring dengan bertambahnya suhu sintering. pengukuran konstanta dielektrik dilakukan pada rentang frekuensi 0,01 sampai $100 \mathrm{kHz}$. Nilai konstanta dielektrik tertinggi berada pada frekuensi terendah. Nilai konstanta dielektrik semakin tinggi seiring dengan bertambahnya suhu sintering.

Kata kunci: $\mathrm{BaSrTiO}_{3}$, konstanta dielektrik, metode co-precipitation

\section{PENDAHULUAN}

Feroelektrik merupakan gejala terjadinya perubahan polarisasi listrik spontan pada material tanpa material tersebut menerima medan listrik dari luar. Material feroelektrik merupakan kelompok material dielektrik yang mempunyai kemampuan untuk mengubah sifat polarisasinya di dalam medan listrik yang sesuai [1]. Salah satu material feroelektrik adalah Barium strontium titanat (BST). Penelitian BST berawal dari penelitian barium titanat (BT) yang menunjukkan bahwa penambahan jumlah ion $\mathrm{Sr}^{2+}$ yang menggantikan ion $\mathrm{Ba}^{2+}$ membuat suhu 
curie menurun ${ }^{[2]}$. Penggantian ion $\mathrm{Ba}$ oleh $\mathrm{Sr}$ dapat mengubah sifat-sifat listriknya serta dapat pula digunakan untuk mengendalikan nilai konstanta dielektrik ${ }^{[3]}$.

Sifat BST dengan rumus $\mathrm{Ba}_{x} \mathrm{Sr}_{1-\mathrm{x}} \mathrm{TiO}_{3}$ tergantung konsentrasi jumlah mol (x). BST dengan nilai $\mathrm{x} \leq 0,75$ memiliki sifat paraelektrik dengan struktur kristalkubik. Sedangkan jika nilai $\mathrm{x} \geq 0,75$, BST akan memiliki sifat feroelektrik dengan struktur kristal tetragonal ${ }^{[2]}$.

Menurut Suasmoro et al. (2000), $\mathrm{Ba}_{1-\mathrm{x}} \mathrm{Sr}_{\mathrm{x}} \mathrm{TiO}_{3}$ yang dibuat pada suhu $700^{\circ} \mathrm{C}$ selama 2 jam menggunakan metode coprecipitation memiliki nilai $\mathrm{a}=\mathrm{b}=3,98262 \AA$ dan $\mathrm{c}=3,99721 \AA^{[3]}$. Menurut Khollam et al. (2005), $\mathrm{Ba}_{1-\mathrm{x}} \mathrm{Sr}_{\mathrm{x}} \mathrm{TiO}_{3}$ yang dibuat dengan metode coprecipitation pada suhu $1300^{\circ} \mathrm{C}$ memiliki konstanta dielektrik sebesar $9500^{[4]}$.

Sampai saat ini, ada beberapa metode yang digunakan untuk mensintesis $\mathrm{Ba}_{1-}$ ${ }_{x} \mathrm{Sr}_{\mathrm{x}} \mathrm{TiO}_{3}$. Salah satu metode tersebut yaitu metode solid state reaction. Metode ini memiliki kelemahan seperti suhu sintering yang sangat tinggi, masih terkontaminasi dari proses grinding, serta ukuran partikelnya masih besar. Metode lainnya adalah metode co-precipitation. Kelebihan dari metode ini adalah tidak memerlukan suhu tinggi serta pembuatan material $\mathrm{Ba}_{1-x} \mathrm{Sr}_{\mathrm{x}} \mathrm{TiO}_{3}$ dapat dilakukan dalam suhu ruang ${ }^{[5]}$.

Pada makalah ini, $\mathrm{Ba}_{1-\mathrm{x}} \mathrm{Sr}_{\mathrm{x}} \mathrm{TiO}_{3}$ dibuat menggunakan metode coprecipitation dengan variasi suhu sintering yaitu sebesar $600^{\circ} \mathrm{C}, 700^{\circ} \mathrm{C}, 800^{\circ} \mathrm{C}$, dan $900^{\circ} \mathrm{C}$ dengan jumlah mol (x) sebesar 0,2. Variasi suhu ini untuk melihat bagaimana pengaruhnya terhadap karakteristik kekristralan dan konstanta dielektrik.

\section{METODE EKSPERIMEN}

Barium strontium titanat dibuat menggunakan metode co-precipitation. Bahan utama pembuatan $\mathrm{Ba}_{1-\mathrm{x}} \mathrm{Sr}_{\mathrm{x}} \mathrm{TiO}_{3}$ adalah $\mathrm{Ba}(\mathrm{OH})_{2}, \mathrm{Sr}\left(\mathrm{NO}_{3}\right)$, $\mathrm{Ti}\left(\mathrm{C}_{4} \mathrm{H}_{9} \mathrm{O}\right)_{4}$, dan $\mathrm{C}_{2} \mathrm{H}_{2} \mathrm{O}_{4}$ (asam oksalat). Asama oksalat dilarutkan ke dalam isopropanol (IPA). Larutan tersebut diaduk menggunakan magnetic stirrer. $\mathrm{Ti}\left(\mathrm{C}_{4} \mathrm{H}_{9} \mathrm{O}\right)_{4}$ dilarutkan ke dalam IPA dan diaduk secara manual. Larutan tersebut ditambahkan ke dalam larutan asam oksalat yang masih dalam pengadukan menggunakan magnetic stirrer. $\mathrm{Ba}(\mathrm{OH})_{2}$ dan $\mathrm{Sr}\left(\mathrm{NO}_{3}\right)$ ditambahkan secara bersamaan ke dalam larutan. Air destilasi ditambahkan ke dalam setetes demi setetes. Setelah penambahan air destilasi, sampel diendapkan selama semalam dalam suhu ruang. Langkah berikutnya adalah pencucian dan pengeringan menggunakan oven pada suhu $100^{\circ} \mathrm{C}$ selama 5 jam. Sampel dicetak menjadi bulk menggunakan instrumen press hidrolik sebelum proses sintering. Sintering dilakukan pada suhu $600^{\circ} \mathrm{C}, 700^{\circ} \mathrm{C}, 800^{\circ} \mathrm{C}$ and $900^{\circ} \mathrm{C}$.

Karakterisasi struktur mikro dari sampel dilakukan menggunakan instrumen XRD dengan $\lambda=1,5406 \AA$ dan step scan $0,25^{\circ}$ dan step size $1,25 \mathrm{dt}$. Pengujian ini 
dilakukan untuk mengetahui ukuran kristal, parameter kisi, serta derajat kekistralan. Nilai ukuran kristal dapat diperoleh menggunakan Persamaan $1^{[6]}$.

$$
D=K \lambda B \cos \theta_{B}
$$

Dimana, $D=$ ukuran kristal $(\mathrm{nm}), \quad K=$ konstanta scherrer (paraelektrik=0,9, feroelektrik=1), $\lambda=$ panjang gelombang x-ray $(\mathrm{nm}), B=\mathrm{FWHM}$ (radian), $\theta_{B}=$ sudut difraksi Bragg $\left(^{\circ}\right)$.

Nilai derajat kekristalan diperoleh menggunakan Persamaan 2.

$$
\text { Derajat kekristalan }=\frac{I_{\text {puncak maks }}-I_{\text {puncak } \min }}{I_{\text {puncak maks }}}
$$

Data pengujian menggunakan instrumen XRD juga dianalisis menggunakan software General Structure Analysis Software (GSAS) denganmetode Retvield. Karakterisasi sifat listrik dari sampel dilakukan menggunakan instrumen LCR meter. Pengujian ini dilakukan untuk mengetahui nilai konstanta dielektrik. Nilai konstanta dielektrik dihitung menggunakan Persamaan $3^{[7]}$.

$$
k=\frac{C d}{\varepsilon_{0} A}
$$

Dimana $C=$ kapsitansi kapasitor (Farad), $k=$ konstanta dielektrik, $\varepsilon_{0}=$ permitivitas ruang hampa $=8,85 \times 10^{-12} \mathrm{~F} / \mathrm{m}, A=$ luas permukaan plat kapasitor $\left(\mathrm{m}^{2}\right), d=$ jarak kedua plat kapasitor $(m)$

\section{HASIL DAN PEMBAHASAN}

Hasil pengujian berupa difraktogram berupa grafik hubungan antara intensitas dengan $2 \theta$. Dari grafik tersebut didapat hasil berupa ukuran kristal, parameter kisi, derajat kekristalan, dan struktur kristal dari $\mathrm{Ba}_{0,8} \mathrm{Sr}_{0,2} \mathrm{TiO}_{3}$. 


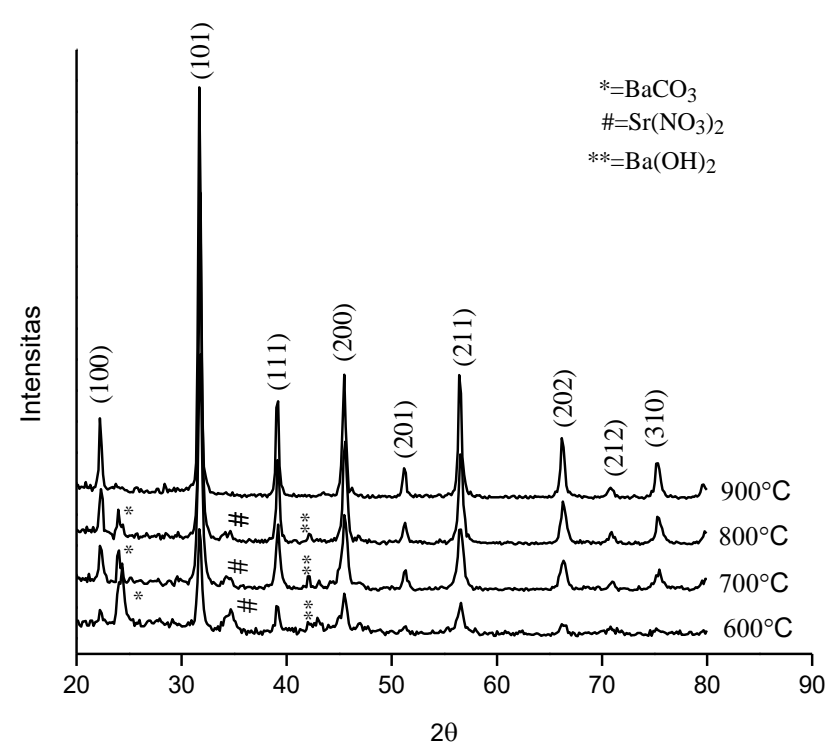

Gambar 1. Pola difraksi $\mathrm{Ba}_{0,8} \mathrm{Sr}_{0,2} \mathrm{TiO}_{3}$ variasi suhu sintering $600^{\circ} \mathrm{C}, 700^{\circ} \mathrm{C}, 800^{\circ} \mathrm{C}$, dan $900^{\circ} \mathrm{C}$

Gambar1 menunjukkan pola difraksi $\mathrm{Ba}_{0,8} \mathrm{Sr}_{0,2} \mathrm{TiO}_{3}$ pada suhu sintering $600^{\circ} \mathrm{C}$, $700^{\circ} \mathrm{C}, 800^{\circ} \mathrm{C}$ dan $900^{\circ} \mathrm{C}$. Pada Gambar tersebut terdapat puncak lain yaitu puncak $\mathrm{BaCO}_{3}$ bertanda $(*)$, puncak $\mathrm{Sr}\left(\mathrm{NO}_{3}\right)_{2}$ bertanda (\#), dan puncak $\mathrm{Ba}(\mathrm{OH})_{2}$ bertanda (**). Adanya puncak lain dalam sampel $\mathrm{Ba}_{0,8} \mathrm{Sr}_{0,2} \mathrm{TiO}_{3}$ menunjukkan bahwa campuran $\mathrm{Ba}_{0,8} \mathrm{Sr}_{0,2} \mathrm{TiO}_{3}$ belum bereaksi secara sempurna. Puncak-puncak yang diidentifikasi bukan milik $\mathrm{Ba}_{0,8} \mathrm{Sr}_{0,2} \mathrm{TiO}_{3}$ sudah tidak ada pada suhu sintering $900^{\circ} \mathrm{C}$. Hal tersebut menandakan bahwa $\mathrm{Ba}_{0,8} \mathrm{Sr}_{0,2} \mathrm{TiO}_{3}$ sudah terbentuk sempurna pada suhu sintering $900^{\circ} \mathrm{C}$.bahwa suhu sintering tidak mempengaruhi sudut difraksi, namun berpengaruh terhadap intensitas puncaknya. Semakin tinggi intensitas pada sampel, maka semakin banyak intensitas yang ditangkap oleh detektor sehingga semakin tinggi ikatan antar atom dan keteraturan atom pada sampel.

$\underline{\text { Tabel 1. Ukuran butir dan derajat kekristalan } \mathrm{Ba}_{0,8} \mathrm{Sr}_{0,2} \mathrm{TiO}_{3} \text { variasi suhu sintering }}$

\begin{tabular}{ccc} 
Suhu Sintering $\left({ }^{\circ} \mathrm{C}\right)$ & $\mathrm{D}(\mathrm{nm})$ & Derajat Kekristalan $(\%)$ \\
\hline 600 & 22,49 & 89,23 \\
700 & 22,70 & 95,70 \\
800 & 27,85 & 96,14 \\
900 & 28,43 & 97,29 \\
\hline
\end{tabular}

Tingkat keteraturan struktur atom pada suatu material dinyatakan dengan derajat kekristalan. Derajat kekristalan ditunjukkan pada Tabel 1. Derajat kekristalan $\mathrm{Ba}_{0,8} \mathrm{Sr}_{0,2} \mathrm{TiO}_{3}$ semakin tinggi seiring dengan kenaikan suhu sintering. Hal ini disebabkan semakin tinggi suhu sintering, semakin tinggi intensitas setiap sampel sehingga ikatan antar atom-atom semakin kuat dan teratur. Tabel 1 juga 
menunjukkan nilai ukuran kristal $\mathrm{Ba}_{0,8} \mathrm{Sr}_{0,2} \mathrm{TiO}_{3}$. Ukuran kristal juga semakin meningkat seiring meningkatnya suhu sintering. Ukuran kristal didapatkan dengan mengukur lebar setengan puncak tertinggi atau Full Width Half Maximum (FWHM). Nilai FWHM dapat diketahui menggunakan Sofware OriginPro 8. Semakin tinggi suhu sintering, semakin semakin besar energi yang diterima oleh atom-atom untuk berdifusi dan beraglomerasi. Semakin banyak atom yang berdifusi dan beraglomerasi, maka semakin besar ukuran kristal $\mathrm{Ba}_{0,8} \mathrm{Sr}_{0,2} \mathrm{TiO}_{3}$.

Tabel 2 merupakan tabel parameter kisi $\mathrm{Ba}_{0,8} \mathrm{Sr}_{0,2} \mathrm{TiO}_{3}$ variasi suhu sintering. Nilai parameter kisi di semua suhu tidak terlalu berbeda jauh. Hal tersebut menunjukkan bahwa suhu sintering tidak mempengaruhi parameter kisi. Nilai tetragonalitas (c/a) untuk kristal dengan struktur tetragonal bernilai lebih dari satu karena c>a.

Tabel 2. Parameter kisi dan tetragonalitas $\mathrm{Ba}_{0,8} \mathrm{Sr}_{0,2} \mathrm{TiO}_{3}$ variasi suhu sintering

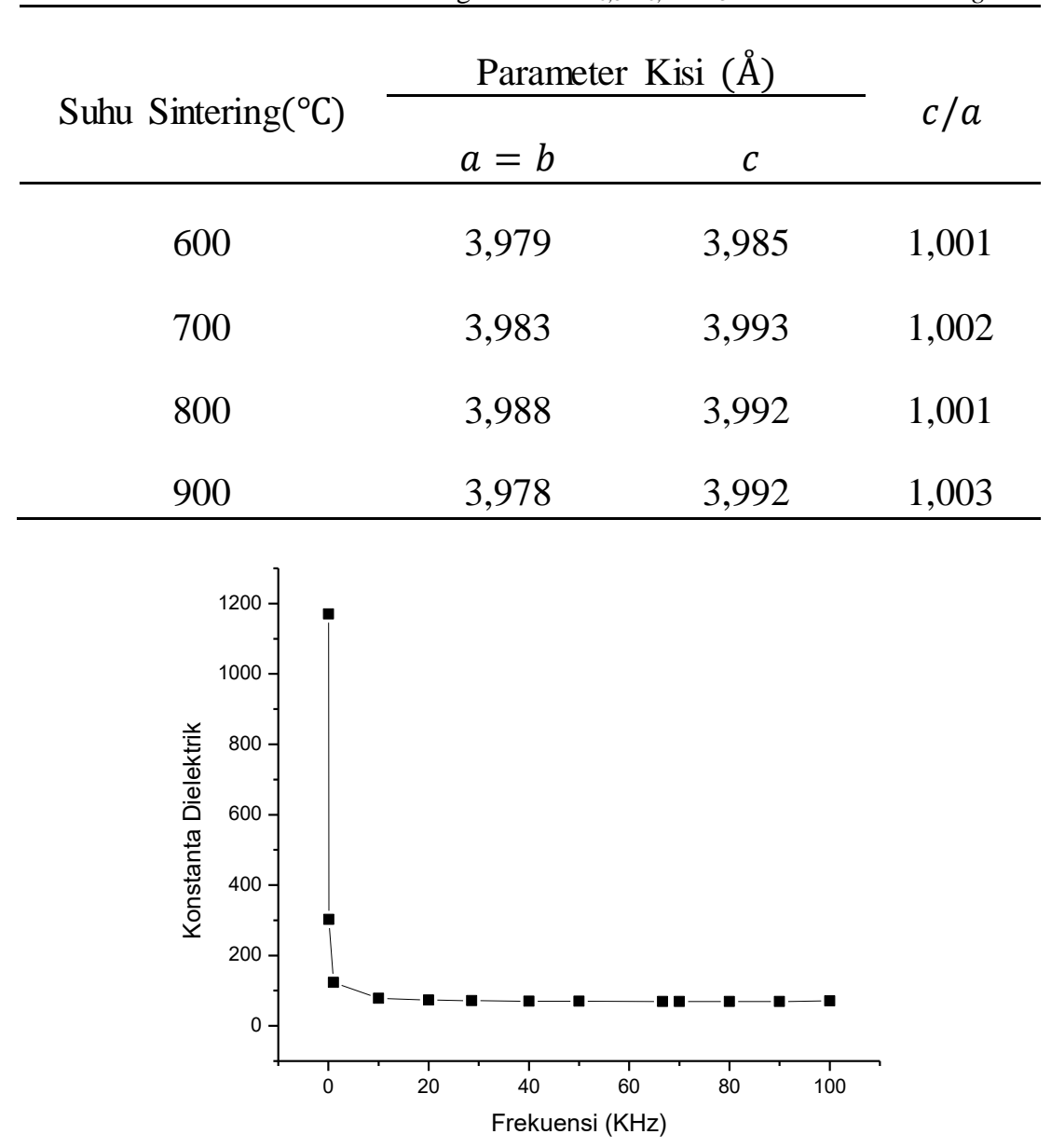

Gambar 2. Grafik konstanta dielektrik terhadap perubahan frekuensi

Pengukuran konstanta dielektrik dilakukan dari frekuensi 0,01 sampai $100 \mathrm{kHz}$. Gambar 2 menunjukkan hasil pengukuran nilai konstanta dielektrik menurun seiring dengan bertambahnya frekuensi. Nilai konstanta dielektrik paling tinggi terdapat pada frekuensi terendah yaitu pada frekuensi $0,01 \mathrm{kHz}$. Nilai konstanta 
dielektrik pada frekuensi $0,01 \mathrm{kHz}$ pada suhu sintering $600^{\circ} \mathrm{C}, 700^{\circ} \mathrm{C}, 800^{\circ} \mathrm{C}$, dan $900^{\circ} \mathrm{C}$ berturut-turut adalah 662, 977, 1170, dan 1594.

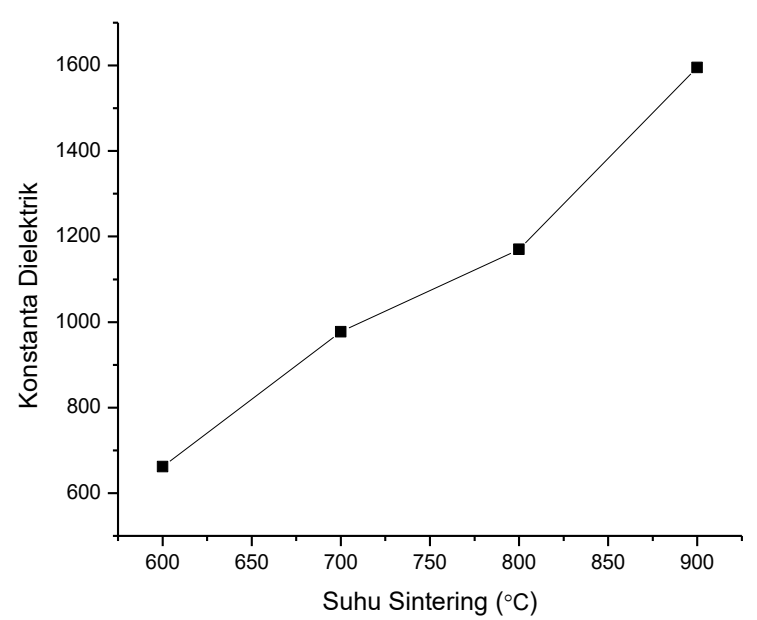

Gambar 3. Grafik hubungan konstanta dielektrik terhadap suhu sintering

Gambar 3 menunjukkan bahwa nilai konstanta dielektrik naik seiring dengan kenaikan suhu sintering. Hal tersebut terjadi karena semakin tinggi suhu sintering maka energi yang diterima oleh atom-atom untuk berdifusi dan beraglomerasi juga semakin besar, sehingga dapat memperbesar ukuran butir yang dihasilkan. Semakin besar ukuran butir menyebabkan domain-domain kristal semakin banyak, sehingga menyebabkan muatan semakin besar. Semakin besar muatan, maka semakin besar kapasintansi. Konstanta dielektrik menjadi lebih besar seiring lebih besarnya kapasitansi.

\section{KESIMPULAN}

Pengaruh variasi suhu sintering terhadap struktur mikro dan sifat listrik diamati pada penelitian ini. Hasil karakterisasi struktur mikro menunjukkan bahwa semakin tinggi suhu sintering, maka nilai ukuran kristal semakin tinggi. $\mathrm{Ba}_{0,8} \mathrm{Sr}_{0,2} \mathrm{TiO}_{3}$ yang di-sintering pada suhu $600^{\circ} \mathrm{C}, 700^{\circ} \mathrm{C}, 800^{\circ} \mathrm{C}$ dan $900^{\circ} \mathrm{C}$ terbentuk dengan ukuran kristal 22,49 $\mathrm{nm}, 22,70 \mathrm{~nm}, 27,85 \mathrm{~nm}$, dan 28,43 $\mathrm{nm}$. Nilai konstanta dielektrik memiliki nilai maksimal pada frekuensi terendah yaitu $0,01 \mathrm{kHz}$. Besar masingmasing nilai konstanta dielektrik pada frekuensi tersebut untuk suhu sintering $600^{\circ} \mathrm{C}, 700^{\circ} \mathrm{C}, 800^{\circ} \mathrm{C}$ dan $900^{\circ} \mathrm{C}$ berturut-turut adalah $662,977,1170$, dan 1594. 


\section{DAFTAR PUSTAKA}

1 Sunandar, C. (2006). Penumbuhan Film BaxSr1-xTiO3 dan Observasi Sifat Ferroelektriknya. Skripsi, Program Studi Fisika FMIPA IPB.

2 Dus, B. W., Czekaj, A. L., Orkisz, T., Adamczyk, M., Osinska, K., Kozielski, L \& Czekaj, D. (2007). The Sol-Gel Synthesisof Barium Stronsium Titanate Ceramics. Material Science-Poland,25 (3).

3 Suasmoro, S., Pratapa, S., Hartanto, D., Setyoko, D. \& Dani, U. M. (2000). The Characterization of Mixed Titanate $\mathrm{Ba}_{1-x} \mathrm{Sr}_{\mathrm{x}} \mathrm{TiO}_{3}$ Phase Formation from Oxalate Coprecipitated Precursor. Journal of Europian Ceramic Siciety, 20, 309-314.

4 Khollam, Y. B., Deshpande, S. B., Potdar, H. S., Bhoraskar, S. V., Sainkar, S. R. \& Date, S. K. (2005). Simple Oxalate Precursor Route for The Preparation of Barium-Strontium Titanate: Ba1-xSrxTiO3 Powders. Material Latters, 57, 63-74.

5 Enhessari, M., Parvis, A., Ozaee, K. \& Abyanah, H. H. (2011). Synthesis and Characterization of Barium Stronsium Titanate (BST) Micro/nanostructure Prepared by Improved Methods. International Journal of Nano Dimension, 85-103.

6 Noh, T., Kim, S. \& Lee, C. (1995). Chemical Preparation of BariumStrontium Titanate. Bulletin of the Korean Chemical Society, 16, 1180-1184

7 Griffiths, D. J. (1999). Introduction of Electrodynamics. New Jersey: PrenticeHall. 